\title{
Chlamydia pecorum detection in aborted and stillborn lambs from Western Australia
}

\author{
Tom Clune', Shane Besier², Sam Hair², Serina Hancock', Amy Lockwood', Andrew Thompson', \\ Martina Jelocnik ${ }^{3+}$ and Caroline Jacobson ${ }^{1 *}+$ (B)
}

\begin{abstract}
Lamb survival is an important welfare and productivity issue for sheep industries worldwide. Lower lamb survival has been reported for primiparous ewes, but the causes of this are not well studied. The aim of this study was to determine causes of perinatal deaths for lambs born to primiparous ewes in Western Australia, and identify if infectious diseases are implicated. Lamb mortality from birth to marking were determined for 11 primiparous ewe flocks on 10 farms in Western Australia. Lamb mortality from birth to marking averaged 14\% for single-born and 26\% for multiple-born lambs. Lamb necropsies $(n=298)$ identified starvation-mismosthering-exposure (34\%), dystocia (24\%) and stillbirth (15\%) as the most common causes of perinatal lamb death. There was no evidence of exotic abortigenic pathogens in aborted and stillborn lambs $(n=35)$. Chlamydia pecorum was detected by qPCR in $15 / 35$ aborted and stillborn lambs on 5/6 farms. Preliminary molecular characterisation of C. pecorum detected in samples from aborted and stillborn lambs $(n=8)$ using both Multilocus Sequence Typing and ompA genotyping indicated all strains were genetically identical to previously described pathogenic livestock strains, denoted ST23, and dissimilar to gastrointestinal strains. High frequency of detection of a pathogenic C. pecorum strains ST23 associated with ovine abortion and stillbirth on multiple farms located across a wide geographic area has not been previously reported. Chlamydia pecorum may contribute to reproductive wastage for primiparous sheep in Western Australia. Further investigation to understand C. pecorum epidemiology and impact on sheep reproduction is warranted.
\end{abstract}

Keywords: Chlamydia, Sheep, Reproduction, Abortion, Stillbirth, Dystocia, Lamb survival, Necropsy

\section{Introduction}

Improving lamb survival is an important economic and welfare issue for sheep industries worldwide. Approximately $10 \%$ of single-born lambs and $30 \%$ of twin-born lambs die prior to weaning under extensive grazing conditions across Australia, with most losses occurring in the first $48 \mathrm{~h}$ of life [1-3]. The starvation-mismosthering-exposure complex, stillbirths, and dystocia are the most common causes of lamb mortality during the perinatal period $[1,2,4]$. Lower lamb survival has been

\footnotetext{
*Correspondence: C.Jacobson@murdoch.edu.au

${ }^{\dagger}$ Martina Jelocnik and Caroline Jacobson—Joint senior author

${ }^{1}$ Centre for Animal Production and Health, Murdoch University, South Street, Murdoch, WA 6150, Australia

Full list of author information is available at the end of the article
}

reported for primiparous ewes compared to adult flocks in Australia [5-7] and overseas [6, 8-11]. However, causes of mortality for lambs born to primiparous ewes are not well described and it is not clear if the main factors contributing to lamb mortality in primiparous ewes are similar to those for multiparous ewes.

Infectious diseases may contribute to lamb mortality through abortion, stillbirths and birth of weak lambs that are more likely to die soon after birth. Campylobacteriosis, listeriosis and toxoplasmosis were the most common aetiological agents identified in sheep abortion investigations submitted to Australian veterinary diagnostic laboratories between 2006 and 2019 $[12,13]$. This is consistent with older reports describing these as the most common infectious causes of 
abortion and perinatal mortality in Australian sheep [14-17]. Sporadic abortion associated with Chlamydia pecorum has been reported in sheep from Australia $[12,18]$ and overseas $[19,20]$, but the epidemiology of C. pecorum-associated abortion in sheep remains poorly understood.

Primiparous ewes may be more susceptible to infectious diseases, as younger ewes are less likely to have developed immunocompetency to infection prior to pregnancy [21, 22]. Most recent Australian studies that included lamb necropsies were conducted with multiparous ewes, and cause of death was assigned based on gross post-mortem findings without adjunct laboratory investigation [2, 23-27]. In general, relatively few investigations for abortion and perinatal lamb death are submitted to veterinary diagnostic laboratories for exclusion of infectious diseases [12]. Consequently, the role of infectious diseases as a contributor to mortality of lambs born to primiparous ewes are not well described and it is possible that the contribution of infectious disease to perinatal mortality may be underrecognized.

The aim of this study was to determine the common causes of perinatal death for lambs born to primiparous ewes, and whether infectious disease was implicated. In doing so, we identified C. pecorum in a surprisingly high proportion of aborted and stillborn lambs from multiple farms, and subsequently expanded the study to determine molecular characteristics for $C$. pecorum strains detected in aborted and stillborn lambs.

\section{Materials and methods}

\section{Animals and study sites}

Eleven flocks of primiparous ewes from ten farms were monitored between the start of mating and lamb marking at approximately 6 weeks from the start of lambing (Table 1). All farms were located in southern Western Australia in a region with Mediterranean climate characterised by hot dry summer and cool wet winter.

On each farm, Merino or non-Merino ewes were mated as either ewe lambs (7-10 months, $n=7$ flocks) or primiparous yearling ewes (18-20 months, $n=4$ flocks; Table 1). All rams were of the same breed as the ewes to which they were joined. Rams were confirmed seronegative for Brucella ovis prior to mating using a modified complement fixation test [28] where three local B. ovis isolates were used as the antigen (DDLS freeze-dried culture collection numbers $0735,1655,1794)$. On two farms, ewes were artificially inseminated followed by a period of natural mating. All other flocks were mated naturally with an average mating period of 38 days (range 32-46 days). All ewes were managed as per standard farm practice including use of body condition monitoring to guide nutrition and grazing management, with no experimental interventions imposed by this study other than monitoring of ewes and lambs as described (Table 1).

\section{Measurements}

Ewes were pregnancy scanned via transabdominal ultrasonography at 62-87 days from the start of mating to determine litter size and foetal viability. Ewe body condition score was recorded at approximately 140 days from

Table 1 Characteristics of primiparous ewe flocks from Western Australia

\begin{tabular}{|c|c|c|c|c|c|c|}
\hline Flock code & Year & Location & Ewe breed & $\begin{array}{l}\text { Ewe age at mating } \\
\text { (months) }\end{array}$ & $\begin{array}{l}\text { Pregnant ewes } \\
(n)^{\mathrm{a}}\end{array}$ & $\begin{array}{l}\text { Pre-lambing } \\
\text { body condition } \\
\text { score }^{b}\end{array}$ \\
\hline$A$ & 2018 & Kojonup & Merino & $18-20$ & 186 & 2.7 \\
\hline$B$ & 2018 & Kojonup & Merino & $18-20$ & 178 & 2.7 \\
\hline C & 2019 & Katanning & Merino & $18-20$ & 204 & 2.8 \\
\hline$D$ & 2019 & Broomehill & Merino & $18-20$ & 169 & 2.5 \\
\hline $\mathrm{E}$ & 2019 & Katanning & Merino & $7-9$ & 86 & 2.7 \\
\hline $\mathrm{F} 1$ & 2018 & Narrogin & Composite $^{c}$ & $7-9$ & 148 & 3.1 \\
\hline $\mathrm{F} 2$ & 2019 & Narrogin & Composite $^{c}$ & $7-9$ & 168 & 3.1 \\
\hline G & 2018 & York & $\begin{array}{l}\text { Composite } \& \text { White } \\
\text { Suffolk }\end{array}$ & $7-9$ & 130 & 3.1 \\
\hline $\mathrm{H}$ & 2019 & Kojonup & Composite $^{c}$ & $7-9$ & 151 & 3 \\
\hline I & 2019 & Kojonup & Dorper & $8-10$ & 146 & 3 \\
\hline$J$ & 2019 & Ongerup & White Suffolk & $7-10$ & 103 & 3.1 \\
\hline
\end{tabular}

a Determined by transabdominal ultrasound conducted 62-87 days from the start of mating or artificial insemination

${ }^{\mathrm{b}}$ Average body condition score of the flock assessed approximately 140 days from the start of mating.

${ }^{c}$ Composite: mixed (non-Merino) breed ewes. 
the start of mating using a scale of 1 (very thin) to 5 (very fat) as previously described [29].

Farm staff checked the lambing flocks once or twice daily throughout the lambing period. Lambs were identified with an ear tag and their birth type and dam pedigree were recorded within $24 \mathrm{~h}$ of birth for most (8/11) flocks. The total number of lambs born for each flock was calculated using records of the number of lambs tagged at birth plus the number of dead lambs collected. On farms where tagging at birth was not performed, the number of lambs born was calculated based on number of lambs present at marking plus the number of dead lambs collected. Number of lambs born may have been underestimated at these sites because it is unlikely that all lambs that died were recovered for necropsy.

\section{Lamb necropsies and sample collection}

Lambs that died in the first three days following birth were retained for necropsy to determine cause of death. Dead lambs were either refrigerated $\left(4{ }^{\circ} \mathrm{C}\right)$ or frozen $\left(-20{ }^{\circ} \mathrm{C}\right)$ for up to 5 days before necropsies were performed. One aborted foetus and one foetal membrane were also recovered from Flock F1 prior to the start of lambing and submitted for necropsy and diagnostic testing for infectious agents.

Lamb necropsies were performed by a single person using methods described by Everett-Hincks and Duncan [30]. Briefly, post-mortem examination included recording the weight, sex and details of the external appearance of the lamb along with gross examination of thoracic and abdominal organs. Brain tissues were assessed for lesions only in lambs that had not been frozen. Cause of death was classified according to methods previously described [30], and described in more detail in Additional file 1.

Tissue samples from aborted or stillborn lambs from flocks with at least two lambs classified as abortion or stillbirth were submitted to the Department of Primary Industry and Regional Development Diagnostic Laboratory Service (South Perth, Western Australia). The type of tissues submitted varied between cases (Additional file 2), with liver and placenta submitted for all cases except where these were not available due to predation.

\section{Laboratory investigation}

Histology, bacteriology and molecular diagnostics for endemic and exotic abortigenic agents were performed by the Department of Primary Industry and Regional Development's Diagnostics and Laboratory Services. Bacteriology comprised culture on blood agar plus selective culture for Salmonella spp., Campylobacter spp. and Listeria spp.. Molecular testing included polymerase chain reactions (PCRs) for Brucella spp., Campylobacter spp., Leptospira spp., Toxoplasma gondii, Coxiella burnetii, pestiviruses and Chlamydia spp. that are described in more detail below.

All aborted tissue samples underwent routine bacteriological culture on Columbia agar (Oxoid) with 5\% equine blood and MacConkey agar (Oxoid). Additionally, foetal liver, cotyledon and placenta samples were subject to selective isolation for Listeria, Salmonella and Campylobacter (PathWest Media, Western Australia). All cultures were incubated at $37{ }^{\circ} \mathrm{C}$ with $5 \% \mathrm{CO}_{2}$ except for the Campylobacter cultures which were incubated under microaerophilic conditions.

Histopathology was performed on formalin fixed tissues processed to haematoxylin and eosin (H\&E) slides; a subset of cases was also subjected to immunohistochemistry. Representative specimens were processed from $10 \%$ buffered formalin solution to paraffin embedded tissue in a Logos Milestone histological processer and blocked using standard histological techniques. Sections were trimmed at $4 \mu \mathrm{m}$ thickness and stained to H\&E in a Leica autostainer XL with Leica CV5030 coverslipper. Selected sections were subject to immunohistochemistry with an anti-Chlamydia polyclonal antibody (B47829R, Progen) and an anti-Toxoplasma gondii polyclonal antibody (B65201R, Biodesign). Both antibodies were visualised using the Dako Envision Dual-link system and Dakocytomation $\mathrm{DAB}+$ (both Dako, Agilent) according to the manufacturers' instructions.

\section{Molecular testing - nucleic acid extraction}

DNA extraction was performed using the QIAamp DNA Mini Kit (Qiagen) and run on the automated Qiacube platform (Qiagen) following the Purification of DNA from tissues protocol. RNA was extracted using the MagMAX-96 Viral RNA Isolation Kit (Thermo Fisher Scientific) on the MagMAX Express-96 (Thermo Fisher Scientific) magnetic bead processor.

\section{Molecular testing-Chlamydia spp.}

Chlamydia quantitative polymerase chain reactions (qPCRs), targeting the outer membrane protein A (ompA) gene, were performed on all foetal liver, cotyledon and placenta samples using species-specific assays for the detection of C. pecorum [31], C. abortus and C. psittaci [32]. Positive C. pecorum detections were confirmed via 298 bp and 806 bp Chlamydiales $16 \mathrm{~S}$ rRNA gene fragments PCRs [33] followed by Sanger sequencing.

Chlamydia qPCR assays were performed in $25 \mu \mathrm{L}$ reaction volumes containing $0.5 \mu \mathrm{M}$ of each primer, $0.2 \mu \mathrm{M}$ of probe, $12.5 \mu \mathrm{L}$ of Rotor-Gene Multiplex Master Mix (Qiagen) and $5 \mu \mathrm{L}$ of extracted DNA. The qPCR reactions were run on a Rotor-Gene Q (Qiagen) real-time PCR cycler under the following conditions: 
initial denaturation at $95{ }^{\circ} \mathrm{C}$ for 5 min followed by 45 cycles of $95{ }^{\circ} \mathrm{C}$ for $15 \mathrm{~s}$ and $60{ }^{\circ} \mathrm{C}$ for $15 \mathrm{~s}$ with fluorescent probe acquisition occurring during the $60{ }^{\circ} \mathrm{C}$ annealing/extension step. A $25 \mu \mathrm{L}$ reaction volume was also used for the Chlamydiales PCRs and contained $0.4 \mu \mathrm{M}$ of each primer, $12.5 \mu \mathrm{L}$ of HotStarTaq Master Mix (Qiagen) and $5 \mu \mathrm{L}$ of extracted DNA. Conventional PCR was performed on a DNA Engine (Bio-Rad) thermal cycler under the following conditions: initial denaturation at $95{ }^{\circ} \mathrm{C}$ for $5 \mathrm{~min}$ followed by 40 cycles of $94{ }^{\circ} \mathrm{C}$ for $30 \mathrm{~s}, 55^{\circ} \mathrm{C}$ for $45 \mathrm{~s}$ and $72{ }^{\circ} \mathrm{C}$ for $45 \mathrm{~s}$ with a final elongation step of $72{ }^{\circ} \mathrm{C}$ for $7 \mathrm{~min}$. To minimise contamination risk synthetic positive control gBlocks Gene Fragments (Integrated DNA technologies) were designed for all PCRs.

Conventional PCR amplicons were purified using the Qiaquick PCR purification kit (Qiagen) and forward and reverse sequencing reactions were prepared in $12 \mu \mathrm{L}$ volumes containing approximately $12-18 \mathrm{ng}$ of PCR product and $9.6 \mathrm{pmol}$ of primer. All amplicons were sequenced at the Australian Genome Research Facility (AGRF Perth Node) and sequence and BLAST analysis was performed using Geneious R11 [34].

\section{Molecular testing-other abortifacents}

Screening for Brucella spp. [35], Campylobacter spp. [36], Coxiella burnetii [37, 38], pathogenic Leptospira spp. [39], Toxoplasma gondii (VetMAX T. gondii KitThermo Fisher Scientific) and Pestivirus [40, 41] was undertaken via PCR. Further screening for Brucella spp. [42] was performed at The Australian Centre for Disease Preparedness, Geelong, Victoria. All primer sequences, probes, final concentrations, and cycling conditions for diagnostic PCRs and molecular testing performed in this study are outlined in Additional file 3.

\section{C. pecorum genotyping by Multi Locus Sequence Typing (MLST) and ompA}

Prior to genotyping, the C. pecorum positive DNA samples from six liver and two cotyledon samples taken from eight aborted and/or stillborn lambs from four different farms (Additional file 2) were quantified for C. pecorum genome copy number (tested in duplicate) using standard curve calibrated and High Resolution Melt (HRM) C. pecorum $\mathrm{qPCR}$ assay [43]. The genome copy number $/ \mu \mathrm{L}$ in samples ranged from $3.41 \times 10^{2}-2.47 \times 10^{5}$ copies $/ \mu \mathrm{L}$ DNA template, with geometric mean of $7.26 \times 10^{3}$ copies $/ \mu \mathrm{L}$ (Table 2). The $C$. pecorum-specific MLST $[44,45]$ and $o m p A$ gene sequence analyses [46] are the most commonly used molecular typing targets for C. pecorum, due to their recognised congruence with whole-genome phylogeny. Full-length ompA genotyping [47] and C. pecorum MLST [45] were applied as previously described to these eight C. pecorum positive DNA samples.

The resultant MLST sequences were confirmed for sequence type (ST) by using the online Chlamydiales PubMLST database [48]. Both concatenated C. pecorum MLST, and ompA sequence and phylogenetic analyses were performed in GeneiousPrime 2020 [34]. The concatenated MLST sequences of eight samples from this study were aligned using ClustalOmega (as implemented in Geneious) to other 36 publicly available livestock $C$. pecorum MLST sequences retrieved from the Chlamydiales PubMLST database [48]. Using the concatenated MLST sequences 3095 bp alignment for the $44 C$. pecorum global and Australian livestock strains, we have constructed a mid-point rooted approximately-maximum-likelihood phylogenetic tree, using FastTree 2.1.11 [49].

The ompA sequences from this study were analysed by BLASTn [50] to evaluate their \% sequence similarity to Top BLAST hits, and aligned using ClustalOmega (as implemented in Geneious) to other publicly available $C$.

Table 2 Mean C. pecorum loads detected by qPCR, and sequence type and sequence identity identified using MLST and ompA

\begin{tabular}{|c|c|c|c|c|c|}
\hline Strain name & Tissue & Mean Ct & $\begin{array}{l}\text { Mean qPCR Loads } \\
\text { (copies/uL) }\end{array}$ & MLST & $\begin{array}{l}\text { ompA \% } \\
\text { sequence } \\
\text { identity }\end{array}$ \\
\hline FarmF1_Foetus1 & Cotyledon & 21.53 & 10552 & ST 23 & $100 \%$ E58 \\
\hline FarmF1_StillbornLamb2 & Liver & 21.24 & 12900 & ST 23 & $100 \%$ E58 \\
\hline FarmF1_Foetus3 & Liver & 18.46 & 88353 & ST 23 & $100 \%$ E58 \\
\hline FarmF1_StillbornLamb4 & Liver & 24.69 & 1176 & ST 23 & $100 \%$ E58 \\
\hline FarmA_StillbornLamb1 & Liver & 26.47 & 341 & ST 23 & $100 \%$ E58 \\
\hline FarmH_StillbornLamb1 & Liver & 22.09 & 7110 & ST 23 & $100 \%$ E58 \\
\hline FarmH_StillbornLamb2 & Cotyledon & 16.97 & 247296 & ST 23 & $100 \%$ E58 \\
\hline Farm」_StillbornLamb & Liver & 25.06 & 911 & ST 23 & $100 \%$ E58 \\
\hline
\end{tabular}


pecorum ompA sequences retrieved from GenBank [51]. Using the 980 bp ompA alignment for the eight C. pecorum strains described in this study and additional 20 previously described strains, we constructed a mid-point rooted Bayesian phylogenetic tree, using MrBayes [52] as implemented in GeneiousPrime (Figure 1). The tree parameters included: GTR +I + G nucleotide substitution model, with four Markov Chain Monte Carlo chains of million generations, subsampled every 10000 runs, and 100000 trees discarded. The ompA sequences from this study were deposited in Genbank under accession numbers MW273771-MW273778. The MLST sequences were deposited in the Chlamydiales PubMLST database [48].

\section{Statistical analyses}

Lamb mortality (\%) between birth and marking for single-born lambs and multiple-born lambs (twins and triplets) were compared using two-tailed z-test [53]. Only farms where lambs were tagged at birth (Flocks A, B, C, E, G, H, I, J) were included in calculation of mortality for single- and multiple-born lambs. The proportion of cases with C. pecorum detected for each ewe age category (ewe lambs and yearling ewes) were compared using twotailed z-test [53].

\section{Results}

\section{Lamb mortality}

From a total of 1963 lambs born, 1395 individual lamb records (including birth type, dam pedigree and survival) were available. Lamb mortality for study flocks are outlined in Additional file 4. Overall, lamb mortality from birth to marking ranged $12.6-27.1 \%$ for Merino yearling flocks and $9.3-40.7 \%$ for non-Merino ewe lamb flocks. Mortality rate for multiple-born lambs (twins or triplets) was $12 \%$ higher than for single-born lambs $(P \leq 0.001)$. One aborted foetus was recovered from Flock F1, and sequential pregnancy ultrasounds identified $7 \%$ of ewes with evidence of pregnancy loss occurring between day 80 and 117 from the start of mating in that flock. No overt evidence of outbreak of abortion ("abortion storm") or ewe illness was observed by the farmers in any of the flocks during the study.

\section{Necropsies and cause of death}

A total of 298 lamb necropsies were performed, which represented $69.1 \%$ of lambs that died between birth and marking. Remaining cases without necropsy either were not recovered by the farmers or died after $72 \mathrm{~h}$ of age.

The cause of death assigned at necropsy are shown in Additional file 5. Cause of death was established for $76 \%(227 / 298)$ of cases. The starvation-mismosthering-exposure complex, dystocia, and stillbirths accounted for $96 \%(218 / 227)$ of cases where cause of death was identified. Predation and decomposition were reported for $26 \%$ of necropsies. Overall, abortion, prematurity and stillbirth represented $21 \%$ necropsies where a cause of death category was assigned. Ewe death during the lambing period $(n=16)$ and subsequent death of their progeny was associated with 5\% (23/431) lamb mortalities from birth to marking.

\section{Laboratory investigation for abortion and stillbirth cases- pathogen detection}

Specimens for 35 cases classified as abortion or stillbirth from six farms were tested for evidence of infectious disease (Table 3 and Additional file 2). Chlamydia pecorum DNA was detected by qPCR in 39\% (13/33) of stillborn or premature cases and $100 \%(2 / 2)$ of abortion cases, with C. pecorum detected at five of the six farms (Table 3). Chlamydia pecorum DNA detection in aborted or stillborn progeny was higher for cases born to ewe lambs $(64 \%, 14 / 22)$ compared with yearling Merino ewes $(8 \%$, $1 / 13 ; P=0.001)$.

The only abortigenic bacteria isolated via culture was Trueperella pyogenes $(n=2)$, including in one case where C. pecorum was concurrently detected using qPCR. Toxoplasma gondii, Listeria spp., Campylobacter fetus, Campylobacter jejuni and exotic abortigenic agents $(C$. abortus, B. melitensis, S. enterica serovar Abortusovis) were not detected by culture or molecular diagnostics (Table 3).

\section{Laboratory investigation for abortion and stillbirth cases- histopathology}

The majority of tissues submitted had significant autolysis and/or had been frozen which negatively impacted histopathological assessment (Additional file 6). In addition, due to the opportunistic nature of some of the sample collection, the range of tissues available for examination was variable, which prevented standardised evaluation of every individual. Cases where fixed tissues were available for histological assessment $(n=17)$ are summarised in Additional file 6. For cases in which C. pecorum was detected by qPCR and fixed tissue were available for histopathology $(n=9)$, lesions observed included placentitis $(n=4)$ epicarditis $(n=3)$, meningitis and encephalitis $(n=2)$, portal hepatitis and renal pyelitis $(n=2)$.

Necrotising placentitis with neutrophilic vasculitis was present for three lambs, with variable placental mineralisation. Another lamb displayed histiocytic infiltration of the allantoic mesenchyme without necrosis or vasculitis. Three of the five placental samples were subjected to Chlamydia IHC and all three were positive, with cytoplasmic staining of trophoblasts and macrophages. 
Epicarditis was noted in three lambs, with mild, multifocal histiocytic and lymphocytic infiltrates present in each. Two lambs displayed a multifocal, histiocytic meningitis, moderate in intensity in one and mild in the second. The more severe case also had multifocal neutrophilic encephalitis and multifocal glial nodule formation. These sections were both Chlamydia spp. and Toxoplasma gondii IHC negative. Two lambs had mild, multifocal infiltrates of histiocytes and lymphocytes in the portal triads of the liver. Two lambs had histiocytic and variably neutrophilic infiltrates in the submucosa of the renal pelvis. The more severe case also displayed several renal epithelial cells distended by small, round, basophilic intracytoplasmic bodies compatible with chlamydial inclusions. The epithelium in the second case had sloughed and was unavailable for examination.

In addition, five lambs displayed meconium or squames in small pulmonary airways and five had a mild macrophage or neutrophil infiltrate in the alveoli. Of the five with inflammatory infiltrates in alveoli, two displayed positive staining of macrophage cytoplasm by Chlamydia IHC.

\section{Molecular characterisation of C. pecorum using MLST and ompA genotyping}

The $C$. pecorum MLST and ompA genotyping was applied to samples from aborted $(n=2)$ or stillborn lambs $(n=6)$ from four farms, and compared to previously reported $C$. pecorum MLST and ompA sequences. The C. pecorum strain sequence types (STs) detected in the aborted and stillborn lambs were denoted as ST23. This genotype was identical to, and clustering with strains previously associated with pathogenicity including recently described ovine abortion from NSW (e.g. NSW_F1, NSW_F2, NSW_F3), ovine polyarthritis and/or conjunctivitis (e.g. Australian Mer_Ovi1_Int and Nar_S24_LE), and sporadic bovine encephalomyelitis (US E58, and Australian NSW/ Bov/SBE, WA_Bov65_Brain) (Figure 1). The remaining C. pecorum STs that have been previously described are mainly sheep and cattle rectal strains, and strains from pig and goat hosts. These other ST clustered in three distinct and diverse larger clades.

Similarly, the ompA sequences detected in aborted and stillborn lambs in this study were genetically identical to previously reported isolates and strains associated with

Table 3 Detection of infectious agents from aborted or stillborn lambs in Western Australia

\begin{tabular}{|c|c|c|c|c|c|c|c|c|}
\hline & \multicolumn{2}{|c|}{ Yearlings } & \multicolumn{6}{|c|}{ Ewe lambs } \\
\hline & Flock A & Flock B & Flock F1 & Flock F2 & Flock H & Flock I & Flock J & Total \\
\hline \multicolumn{9}{|l|}{ Cases submitted $(n)$} \\
\hline Total & 10 & 3 & 10 & 4 & 4 & 2 & 2 & 35 \\
\hline Aborted foetus \& membranes & 0 & 0 & 1 & 0 & 0 & 0 & 0 & 1 \\
\hline Aborted membranes only & 0 & 0 & 1 & 0 & 0 & 0 & 0 & 1 \\
\hline Stillborn lamb & 10 & 3 & 8 & 4 & 4 & 2 & $2^{\mathrm{a}}$ & 33 \\
\hline \multicolumn{9}{|l|}{ Chlamydia spp. } \\
\hline \multicolumn{9}{|l|}{ C.pecorum } \\
\hline qPCR positive & 1 & 0 & 9 & 0 & 3 & 1 & 1 & 15 \\
\hline Sequencing-C. pecorum & 1 & 0 & 4 & 0 & 3 & 1 & 1 & 10 \\
\hline Insufficient amplification & 0 & 0 & 5 & 0 & 0 & 0 & 0 & 5 \\
\hline C. abortus & 0 & 0 & 0 & 0 & 0 & 0 & 0 & 0 \\
\hline C.psittaci & 0 & 0 & 0 & 0 & 0 & 0 & 0 & 0 \\
\hline \multicolumn{9}{|l|}{ Other } \\
\hline Listeria (culture) & 0 & 0 & 0 & 0 & 0 & 0 & 0 & 0 \\
\hline Salmonella (culture) & 0 & 0 & 0 & 0 & 0 & 0 & 0 & 0 \\
\hline Trueperella pyogenes (culture) & - & - & 1 & - & 1 & - & - & 2 \\
\hline Campylobacter (culture) & 0 & 0 & 0 & 0 & 0 & 0 & 0 & 0 \\
\hline Campylobacter (PCR) & 0 & 0 & $2^{b}$ & 0 & 0 & 0 & 0 & $2^{\mathrm{a}}$ \\
\hline Leptospira (PCR) & 0 & 0 & 0 & 0 & 0 & 0 & 0 & 0 \\
\hline Toxoplasma (qPCR) & 0 & 0 & 0 & 0 & 0 & 0 & 0 & 0 \\
\hline Coxiella (qPCR) & 0 & 0 & 0 & 0 & 0 & 0 & 0 & 0 \\
\hline Brucella (PCR) & 0 & 0 & 0 & 0 & 0 & 0 & 0 & 0 \\
\hline Pan-pestivirus (qPCR) & 0 & 0 & 0 & 0 & 0 & 0 & 0 & 0 \\
\hline
\end{tabular}

a Premature twins.

${ }^{\mathrm{b}} \mathrm{C}$. sputorum and C. mucosalis by sequencing (suspected contaminant). 


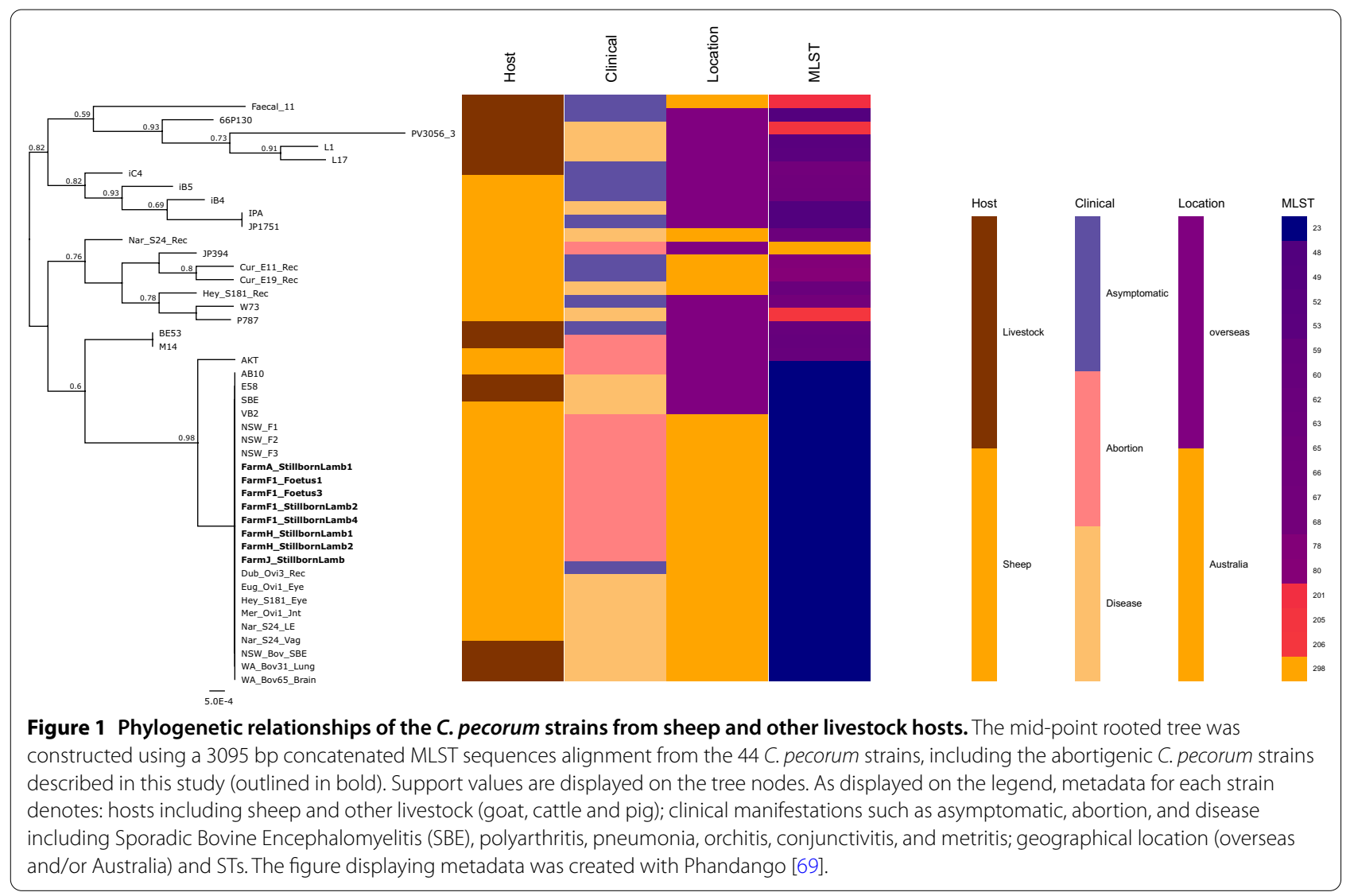

pathogenicity (e.g. Australian Mer/Ovi1/Jnt), US E58, and Australian NSW/Bov/SBE) clustering together in a well-supported clade (Additional file 7). The remaining the ompA sequences from sheep, goat and/or bovine rectal and other strains clustered in several genetically diverse clades (Additional file 7).

\section{Discussion}

The detection of C. pecorum in aborted and stillborn lambs from primiparous ewes from multiple farms was the most striking observation in this study. Chlamydia pecorum has predominantly been associated with polyarthritis [54-56], keratoconjunctivitis [43] and asymptomatic gastrointestinal carriage and faecal shedding in Australian sheep [57]. Abortion due to C. pecorum is sporadic and not commonly reported [12, 18, 20], and the role of C. pecorum as an abortigenic agent is not well defined. Thereby, detection of this organism in aborted and stillborn lambs from multiple farms with no epidemiological or geographical relationship is notable, and $C$. pecorum should be considered as a differential diagnosis for abortion and perinatal mortality in Australian sheep.
Determining the aetiology in abortion and perinatal lamb death investigations is inherently challenging [12], and conclusive diagnosis of disease cannot be made based only on detection of a pathogen in tissue samples. Nevertheless, several observations from this study suggest C. pecorum was a likely aetiological agent associated with abortion and stillbirth on these farms. Firstly, other endemic and exotic abortigenic agents were not detected. Secondly, histopathological changes for cases where $C$. pecorum was detected were consistent with those reported for $C$. abortus and previously described C. pecorum abortion in small ruminants $[18,58,59]$. The high loads of $C$. pecorum detected in placenta and foetal liver from aborted and stillborn lambs (Table 2) was consistent with observations for other clinical diseases associated with $C$. pecorum $[44,55,56]$. Finally, MLST and ompA characterisation of high load C. pecorum DNA from aborted and stillborn lambs identified ST23 type strains that were identical to other globally distributed ST23 strains associated with pathology in sheep and cattle, including abortion [18, 60], arthritis $[61,62]$ and conjunctivitis $[61,62]$ in sheep, and sporadic bovine encephalopathy in cattle [44,61]. Emerging evidence of abortigenic potential of C. pecorum is perhaps 
not surprising given the closely related $C$. abortus is an important cause of abortion in sheep in other countries, and C. psittaci is a cause of abortion in horses [63, 64].

Chlamydia pecorum was detected in aborted and stillborn lambs from five out of six farms. However, the degree to which C. pecorum ST23 contributed overall lamb mortalities could not be determined. Infectious disease screening was not conducted for lambs that died from causes other than abortion or stillbirth, including those classified as starvation-mismothering. However, similar to other bacterial infections of the pregnant uterus, it is likely that $C$. pecorum-associated placentitis results in a spectrum of outcomes, including abortion, stillbirths, lambs that are born alive, but weak and with low birth weights and poor survival, congenital infections or even normal offspring, depending on the severity of placental pathology and colonisation [18, 65]. Future investigations should determine whether infection contributes to reduced lamb viability, as well as abortion or stillbirth, and factors that impact outcome for infection.

Chlamydia pecorum detection was higher for aborted and stillborn progeny of younger ewes (ewe lambs) compared to yearling ewes. This was consistent with a recent case report from New South Wales, Australia where $C$. pecorum abortion was reported in primiparous ewe lambs, with no evidence of abortion storm in multiparous ewes on the same property [18]. Ewes mated as ewe lambs (under 12 months of age) may be more susceptible to $C$. pecorum ST23 infection and pathology. The reproductive performance of ewe lambs is highly variable. Improved understanding about the impact of C. pecorum ST23 on reproductive performance of ewe lambs and opportunities to mitigate impacts could inform management recommendations to improve their reproductive performance.

Chlamydia pecorum is endemic in Australian livestock $[55,57,61]$, including sheep and cattle, and ubiquitous in livestock worldwide [64]. The route by which ewes became infected was not tested in our study. Faecal-oral transmission has been hypothesised, however mucosal shedding has been reported and transmission routes such as oculo- oral- or nasal contact, sexual transmission or inhalation are plausible [64].

Asymptomatic C. pecorum infections are commonly detected in sheep, with faecal carriage detected $30 \%$ faecal samples over three time points and flock point prevalence ranging 0-94\% in Australian sheep [57]. However, MLST and ompA genotyping has demonstrated ST23 detected in cases of abortion, arthritis and conjunctivitis are distinct from gastrointestinal strains detected in rectal swabs (Figure 1). Therefore, studies that do not characterise C. pecorum ST cannot assess prevalence for the pathogenic ST23 genotype and the epidemiology for $C$. pecorum ST23 in Australian sheep remains poorly understood. Incidence of abortion, conjunctivitis and lameness are typically not reported for flocks included epidemiological studies because these conditions are challenging to detect in extensively managed sheep and may not be evident at the time of sampling. The incidence of conjunctivitis and arthritis was not able to be determined for flocks in our study, however polyarthritis associated with C. pecorum was detected in sheep from Farm F [56].

Overall lamb mortality for flocks in this study was comparable with ranges reported in other Australian studies [1]. Stillbirths accounted for $19 \%$ of necropsies where cause of death was determined, and despite the detection of C. pecorum, was not markedly different to stillbirths as proportion of total losses reported in other Australian studies [2]. Notably, stillbirths and abortion associated with C. pecorum ST23 were detected in flocks without overt evidence of abortion storm (i.e. observation of abortions by the farmer) or illness in ewes that would have normally triggered a veterinary investigation. This suggests $C$. pecorum may be associated with subclinical losses that go undetected on Australian farms, and explains why C. pecorum abortion is not more widely reported.

Listeriosis, campylobacteriosis and toxoplasmosis are the most common infectious causes of abortion and perinatal death in Australian sheep [12, 13]. These diseases are sporadic and were not detected in any of the aborted or stillborn lambs in this study. There was no evidence of exotic infectious diseases. Trueperella pyogenes was cultured in two cases, but the significance of this finding was not clear. Although T. pyogenes has been reported as a primary abortigenic agent $[12,66]$, the commensal nature of the organism on the mucosal surfaces predisposes aborted and birth material to secondary contamination [67]. Regarding the case where both $T$. pyogenes and $C$. pecorum were detected in the same lamb, co-infections with other pathogens has been reported for both species [31, 67]. However, the role of a synergistic interaction between $C$. pecorum and T. pyogenes, precipitating in disease, has not been established. This observation also serves as a reminder to consider mixed and co-infections during abortion investigations.

Starvation-mismosthering-exposure complex and dystocia accounted for most lamb mortalities that occurred in the perinatal period and mortality was higher for multiple-born lambs compared to single-born lambs. This was consistent with studies reported for multiparous ewes in Australia [1, 2, 5, 68], and primiparous ewes in New Zealand $[9,10]$. Strategies to reduce dystocia and starvation-mismosthering-exposure, including provision of adequate shelter for lambing ewes and managing ewe nutrition during pregnancy to optimise lamb 
birthweights may help optimise survival for progeny of primiparous ewes [4].

The ability to assess brain and neurological tissue at necropsy was impacted by freezing of some carcasses and the extent of time lapsed prior to necropsy. This impacted comparison of proportion of mortalities attributable to dystocia relative to other studies that use brain and spinal cord lesion scores to determine cases as dystocia B (stillbirth) or dystocia C (birth injury) where obvious subcutaneous oedema of the head or neck is not present $[2,25]$. Additionally, predation and decomposition were evident in approximately one quarter of necropsies, contributing to number of cases where cause of death could not be determined.

Chlamydia pecorum was detected in abortions and stillborn progeny of primiparous ewes from multiple farms and should be considered as a differential diagnosis for abortion and perinatal mortality in Australian sheep. The $C$. pecorum strains detected from abortions and stillborn lambs belong to the ST23 clade that has previously been associated with abortions in sheep and cattle, and other diseases including polyarthritis, conjunctivitis and sporadic bovine encephalitis. Further investigation to quantify impact of C. pecorum as a cause of abortion, stillbirth or poor lamb viability in sheep, and determine factors that impact infection outcome are warranted. Starvation-mismosthering-exposure complex, dystocia and stillbirths accounted for most lamb mortalities for lambs born to primiparous ewes, which is consistent with that reported for adult ewes.

\section{Abbreviations}

BLAST: Basic local alignment search tool; H\&E: Haematoxylin and eosin; IHC: Immunohistochemistry; MLST: Multilocus sequence typing; ompA: Outer membrane protein A; PCR: Polymerase chain reaction; qPCR: Quantitative polymerase chain reaction; SME: Starvation-mismosthering-exposure complex; ST: Sequence type.

\section{Supplementary Information}

The online version contains supplementary material available at https://doi. org/10.1186/s13567-021-00950-w.

\section{Additional file 1. Cause of death classifications. \\ Additional file 2. Summary data for tissues available for laboratory diagnosis from aborted and stillborn lambs.}

Additional file 3. Primer/probe final concentrations, sequences and cycling conditions for diagnostic PCRs performed during this study.

Additional file 4. Lamb mortality (birth to marking) for lambs born to primiparous ewes in Western Australia.

Additional file 5. Cause of lamb death identified at necropsy.

Additional file 6. Histopathology findings.

Additional file 7. The livestock C. pecorum ompA phylogenetic relationships.
Acknowledgements

We thank the participating farmers who provided access to their animals and facilities, conducted lambing rounds, and collected and stored lambs for necropsy. We thank Richmond Loh and Anna Erickson at DPIRD for assistance with laboratory diagnostic testing through the DPIRD Abortion Surveillance Scheme. We thank Tom La and Nyree Philips for assistance with sample collection. We thank Mieghan Bruce (Murdoch University) for helpful feedback on the manuscript. We thank The Australian Centre for Disease Preparedness for additional molecular screening of Brucella species.

\section{Authors' contributions}

Conceptualization: CJ, TC, MJ, AT; Sample collection: TC, CJ, AL, S. Hancock; Necropsies: TC; Laboratory work: S. Hair, SB, MJ; Funding acquisition: CJ, TC, MJ, S. Hancock; Supervision: CJ, MJ, AT, S. Hancock; Writing (original draft, review and editing): TC, MJ, CJ, SB, AL, AT, S. Hair, S. Hancock. All authors read and approved the final manuscript.

\section{Funding}

Field work was supported with funding from Meat and Livestock Australia (B.AHE.0318). Laboratory diagnostic testing was performed under the Western Australian Ewe Abortion and Newborn Lamb Death Surveillance Program and supported with funding by Australian Government Department of Agriculture in partnership with Australian Wool Innovation as part of the 2020 Science and Innovation Awards for Young People in Agriculture, Fisheries and Forestry awarded to Tom Clune, and by 2019 Australian Research Council Discovery Early Career Research Award (DE190100238) awarded to Martina Jelocnik. Tom Clune was supported with post graduate scholarships from Meat and Livestock Australia and Sheep Industry Business Innovation (Department of Primary Industries and Regional Development, Western Australia).

\section{Declarations}

Ethics approval and consent to participate

All procedures for monitoring ewes and sample collection were conducted according to guidelines of the Australian Code of Practice for the Use of Animals for Scientific Purposes, and were approved by the Murdoch University Animal Ethics Committee (R3004/17).

\section{Consent for publication}

The owners of sheep included in this study have consented to publication of this manuscript.

\section{Competing interests}

None of the authors of this paper have a financial or personal relationship with other people or organisations that could inappropriately influence or bias the content of the paper. The manuscript was approved for publication by two of the funding bodies (Meat and Livestock Australia and Australian Wool Innovation), but neither organisation was involved in the collection, analysis or interpretation of data, or in the writing of the manuscript.

\section{Author details}

${ }^{1}$ Centre for Animal Production and Health, Murdoch University, South Street, Murdoch, WA 6150, Australia. ${ }^{2}$ Department of Primary Industries and Regional Development, South Perth, WA 6151, Australia. ${ }^{3}$ Genecology Research Centre, University of the Sunshine Coast, 90 Sippy Downs Drive, Sippy Downs, QLD 4557, Australia.

Received: 4 March 2021 Accepted: 18 May 2021

Published online: 11 June 2021

\section{References}

1. Hinch GN, Brien F (2014) Lamb survival in Australian flocks: a review. Anim Prod Sci 54:656. https://doi.org/10.1071/AN13236

2. Refshauge G, Brien FD, Hinch GN, van de Ven R (2016) Neonatal lamb mortality: factors associated with the death of Australian lambs. Anim Prod Sci 56:726-735. https://doi.org/10.1071/AN15121 
3. Oldham CM, Thompson AN, Ferguson MB, Gordon DJ, Kearney GA, Paganoni BL (2011) The birthweight and survival of Merino lambs can be predicted from the profile of liveweight change of their mothers during pregnancy. Anim Prod Sci 51:776-783. https://doi.org/10.1071/AN10155

4. Jacobson C, Bruce M, Kenyon PR, Lockwood A, Miller D, Refshauge G, Masters DG (2020) A review of dystocia in sheep. Small Rumin Res 192:106209. https://doi.org/10.1016/j.smallrumres.2020.106209

5. Kleemann DO, Walker SK (2005) Fertility in South Australian commercial Merino flocks: sources of reproductive wastage. Theriogenology 63:2075-2088. https://doi.org/10.1016/j.theriogenology.2004.06.017

6. Knight TW, Oldham CM, Smith JF, Lindsay DR (1975) Studies in ovine infertility in agricultural regions in Western Australia: analysis of reproductive wastage. Aust J Exp Agric Anim Husb 15:183

7. Kilgour R (1992) Lambing potential and mortality in Merino sheep as ascertained by ultrasonography. Aust J Exp Agric 32:311-313. https://doi. org/10.1071/EA9920311

8. Kenyon PR, Thompson AN, Morris ST (2014) Breeding ewe lambs successfully to improve lifetime performance. Small Rumin Res 118:2-15. https:// doi.org/10.1016/j.smallrumres.2013.12.022

9. Young E, Yuan J, Everett-Hincks J (2010) Yearling lambing performance and primary cause of lamb death. Proc NZ Soc Anim Prod 70:96-100

10. McMillan W (1983) Hogget lamb mortality. Proc NZ Soc Anim Prod 43:33-36

11. Pettigrew $E$, Hickson $R$, Blair $H$, Griffiths $K$, Ridler A, Morris S, Kenyon $P$ (2018) Differences in birth weight and neonatal survival rate of lambs born to ewe hoggets or mature ewes. NZ J Anim Sci Prod 78:16-20

12. Clune T, Beetson S, Besier S, Knowles G, Paskin R, Rawlin G, Suter R, Jacobson C (2020) Ovine abortion and stillbirth investigations in Australia. Aust Vet J 99:72-78. https://doi.org/10.1111/avj.13040

13. Refshauge G, Atkinson T, Robertson SM, Hernandez-Jover M, Allworth B, Friend M (2020) Reducing kid loss_-select and protect. Phase 1 final report. Meat and Livestock Australia, North Sydney, Australia. Available at: https://www.mla.com.au/research-and-development/reports/2020/ reducing-kid-loss-select-and-protect---phase-1/. Accessed 1 Feb 2021

14. Broadbent DW (1975) Infections associated with ovine perinatal mortality in Victoria. Aust Vet J 51:71-74. https://doi.org/10.1111/j.1751-0813.1975. tb09408.x

15. Dennis SM (1974) Perinatal lamb mortality in Western Australia. 3 Congenital infections. Aust Vet J 50:507-510. https://doi.org/10.1111/j.17510813.1974.tb14056.x

16. Plant JW, Beh KJ, Acland Helen M (1972) Laboratory findings from ovine abortion and perinatal mortality. Aust Vet J 48:558-561. https://doi.org/ 10.1111/j.1751-0813.1972.tb08011.x

17. Munday BL, Ryan FB, King SJ, Corbould A (1966) Preparturient infections and other causes of foetal loss in sheep and cattle in Tasmania. Aust Vet $J$ 42:189-193. https://doi.org/10.1111/j.1751-0813.1966.tb04687.x

18. Westermann T, Jenkins C, Onizawa E, Gestier S, McNally J, Kirkland P, Zhang J, Bogema D, Manning LK, Walker K, Pinczowski P (2021) Chlamydia pecorum associated sporadic ovine abortion. Vet Pathol 58:114-122. https://doi.org/10.1177/0300985820967451

19. Clemente MLT, Barahona MJB, Andrade MFC, Botelho AR, Vicari N (2011) Diagnosis by PCR-REA of Chlamydophila species infections in late-term abortions of domestic ruminants. Vet Rec 168:619-619. https://doi.org/ $10.1136 / v r . d 889$

20. Williams S (2019) The challenges of an unusual abortion outbreak in a ewe flock. Proc Soc Sheep Beef Cattle Vet NZ Vet Assoc 2019:69-74

21. Quinlivan TD, Joppt AJ (1982) A survey on the incidence and cause of ovine abortion in Hawkes Bay. N Z Vet J 30:65-68. https://doi.org/10. 1080/00480169.1982.34883

22. Dempster RP, Wilkins M, Green RS, de Lisle GW (2011) Serological survey of Toxoplasma gondii and Campylobacter fetus fetus in sheep from New Zealand. N Z Vet J 59:155. https://doi.org/10.1080/00480169.2011.579240

23. Lockwood A, Hancock S, Kearney G, Thompson A (2019) Reducing mob size increases the survival of twin-born Merino lambs when feed-on-offer from pasture is limited and ewes are supplementary fed during lambing. Small Rumin Res 173:65-69. https://doi.org/10.1016/j.smallrumres.2019. 02.008

24. Lockwood A, Hancock S, Paganoni B, Macleay C, Kearney G, Sohi R, Thompson A (2019) Mob size of single-bearing or twin-bearing Merino ewes at lambing may not influence lamb survival when feed-on-offer is high. Animal 13:1311-1318. https://doi.org/10.1017/S175173111800280X
25. Holst PJ, Fogarty NM, Stanley DF (2002) Birth weights, meningeal lesions, and survival of diverse genotypes of lambs from Merino and crossbred ewes. Aust J Agric Res 53:175-181. https://doi.org/10.1071/AR01046

26. Behrendt R, Hocking Edwards JE, Gordon D, Hyder M, Kelly M, Cameron F, Byron J, Raeside M, Kearney G, Thompson AN (2019) Offering maternal composite ewes higher levels of nutrition from mid-pregnancy to lambing results in predictable increases in birthweight, survival and weaning weight of their lambs. Anim Prod Sci 59:1906-1922. https://doi.org/10. 1071/AN18505

27. Robertson SM, Boulton J, Xie G, Neef A, Friend MA (2020) Usefulness of pathological examinations of the central nervous system for monitoring and controlling perinatal lamb mortality. Animal 14:2372-2377. https:// doi.org/10.1017/S1751731120001366

28. Corner LA (1987) Australia and New Zealand standard diagnostic techniques for animal disease: Bovine Brucellosis, Serology. Available at: https://www.agriculture.gov.au/animal/health/laboratories/procedures/ asdt/bovine-brucellosis-serology. Accessed 15 Feb 2021

29. Jefferies B (1961) Body condition scoring and its use in management. Tas J Agric 39:19-21

30. Everett-Hincks J, Duncan S (2008) Lamb post-mortem protocol for use on farm: to diagnose primary cause of lamb death from birth to 3 days of age. Open Vet Sci J 2:55-62. https://doi.org/10.2174/187431880080201 0055

31. Pantchev A, Sting R, Bauerfeind R, Tyczka J, Sachse K (2010) Detection of all Chlamydophila and Chlamydia spp. of veterinary interest using species-specific real-time PCR assays. Comp Immunol Microbiol Infect Dis 33:473-484. https://doi.org/10.1016/j.cimid.2009.08.002

32. Pantchev A, Sting R, Bauerfeind R, Tyczka J, Sachse K (2009) New real-time PCR tests for species-specific detection of Chlamydophila psittaci and Chlamydophila abortus from tissue samples. Vet J 181:145-150. https:// doi.org/10.1016/.tvil.2008.02.025

33. Everett KDE, Bush RM, Andersen AA (1999) Emended description of the order Chlamydiales, proposal of Parachlamydiaceae fam. nov. and simkaniaceae fam. nov., each containing one monotypic genus, revised taxonomy of the family Chlamydiaceae, including a new genus and five new species, and standards for the identification of organisms. Int J Syst Evol Microbiol 49:415-440. https://doi.org/10.1099/00207713-49-2-415

34. Geneious. www.geneious.com/prime/. Accessed 15 Feb 2021

35. Ouahrani-Bettache S, Soubrier M-P, Liautard J-P (1996) IS6501-anchored PCR for the detection and identification of Brucella species and strains. J Appl Bacteriol 81:154-160. https://doi.org/10.1111/j.1365-2672.1996. tb04493.x

36. Linton D, Owen RJ, Stanley J (1996) Rapid identification by PCR of the genus Campylobacter and of five Campylobacter species enteropathogenic for man and animals. Res Microbiol 147:707-718. https://doi.org/ 10.1016/S0923-2508(97)85118-2

37. Banazis MJ, Bestall AS, Reid SA, Fenwick SG (2010) A survey of Western Australian sheep, cattle and kangaroos to determine the prevalence of Coxiella burnetii. Vet Microbiol 143:337-345. https://doi.org/10.1016/j. vetmic.2009.12.002

38. Lockhart MG, Graves SR, Banazis MJ, Fenwick SG, Stenos J (2011) A comparison of methods for extracting DNA from Coxiella burnetii as measured by a duplex qPCR assay. Lett Appl Microbiol 52:514-520. https://doi.org/ 10.1111/j.1472-765X.2011.03034.X

39. Smythe LD, Smith IL, Smith GA, Dohnt MF, Symonds ML, Barnett L, McKay DB (2002) A quantitative PCR (TaqMan) assay for pathogenic Leptospira spp. BMC Infect Dis 2:13. https://doi.org/10.1186/ 1471-2334-2-13

40. Hyndman L, Vilcek S, Conner J, Nettleton PF (1998) A novel nested reverse transcription PCR detects bovine viral diarrhoea virus in fluids from aborted bovine fetuses. J Virol Methods 71:69-76. https://doi.org/10. 1016/S0166-0934(97)00206-1

41. Hoffmann B, Depner K, Schirrmeier H, Beer M (2006) A universal heterologous internal control system for duplex real-time RT-PCR assays used in a detection system for pestiviruses. J Virol Methods 136:200-209. https:// doi.org/10.1016/j.jviromet.2006.05.020

42. López-Goñi I, García-Yoldi D, Marín CM, de Miguel MJ, Muñoz PM, Blasco JM, Jacques I, Grayon M, Cloeckaert A, Ferreira AC, Cardoso R, Corrêa de Sá MI, Walravens K, Albert D, Garin-Bastuji B (2008) Evaluation of a multiplex PCR assay (Bruce-ladder) for molecular typing of all Brucella species, 
including the vaccine strains. J Clin Microbiol 46:3484-3487. https://doi. org/10.1128/jcm.00837-08

43. Jelocnik M, Laurence M, Murdoch F, Polkinghorne A (2019) Detection of Chlamydiaceae in ocular swabs from Australian pre-export feedlot sheep. Aust Vet J 97:401-403. https://doi.org/10.1111/avj.12857

44. Jelocnik M, Forshaw D, Cotter J, Roberts D, Timms P, Polkinghorne A (2014) Molecular and pathological insights into Chlamydia pecorumassociated sporadic bovine encephalomyelitis (SBE) in Western Australia. BMC Vet Res 10:121. https://doi.org/10.1186/1746-6148-10-121

45. Jelocnik M, Polkinghorne A, Pannekoek Y (2019) Multilocus Sequence Typing (MLST) of Chlamydiales. Methods Mol Biol 2042:69-86. https://doi. org/10.1007/978-1-4939-9694-0_7

46. Mohamad KY, Kaltenboeck B, Rahman KS, Magnino S, Sachse K, Rodolakis A (2014) Host adaptation of Chlamydia pecorum towards low virulence evident in co-evolution of the ompA, incA, and ORF663 loci. PLoS One 9:e103615. https://doi.org/10.1371/journal.pone.0103615

47. Islam MM, Jelocnik M, Anstey S, Kaltenboeck B, Borel N, Timms P, Polkinghorne A (2019) In vitro analysis of genetically distinct Chlamydia pecorum isolates reveals key growth differences in mammalian epithelial and immune cells. Vet Microbiol 232:22-29. https://doi.org/10.1016/j.vetmic. 2019.03.024

48. Jolley KA, Bray JE, Maiden MCJ (2018) Open-access bacterial population genomics: BIGSdb software, the PubMLST.org website and their applications. Wellcome Open Res 3:124. https://doi.org/10.12688/wellcomeop enres. 14826.1

49. Price MN, Dehal PS, Arkin AP (2010) FastTree 2-approximately maximum-likelihood trees for large alignments. PLoS One 5:e9490. https://doi. org/10.1371/journal.pone.0009490

50. BLASTn. https://blast.ncbi.nlm.nih.gov/Blast.cgi. Accessed 15 Feb 2021

51. GenBank. www.ncbi.nlm.nih.gov/genbank/. Accessed 15 Feb 2021

52. Huelsenbeck JP, Ronquist F (2001) MRBAYES: Bayesian inference of phylogenetic trees. Bioinformatics 17:754-755. https://doi.org/10.1093/bioin formatics/17.8.754

53. Sergeant ESG (2021) Epitools epidemiological calculators. Ausvet Pty Ltd. Available at: http://epitools.ausvet.com.au. Accessed 20 Feb 2021

54. Lloyd J, Yang R, Kessell A, Ryan U, Schröder J, Rutley D (2017) Detection of Chlamydia pecorum in joints trimmed from ovine carcases with arthritis at an abattoir in southern Australia. Small Rumin Res 150:80-86. https://doi. org/10.1016/j.smallrumres.2017.03.007

55. Walker E, Moore C, Shearer P, Jelocnik M, Bommana S, Timms P, Polkinghorne A (2016) Clinical, diagnostic and pathologic features of presumptive cases of Chlamydia pecorum-associated arthritis in Australian sheep flocks. BMC Vet Res 12:193. https://doi.org/10.1186/s12917-016-0832-3

56. Ostfeld N, Islam MM, Jelocnik M, Hilbe M, Sydler T, Hartnack S, Jacobson C, Clune T, Marsh I, Sales N, Polkinghorne A, Borel N (2020) Chlamydia pecorum-induced arthritis in experimentally-induced and naturally infected sheep. Vet Pathol 58:346-360. https://doi.org/10.1177/03009 85820973461

57. Yang R, Jacobson C, Gardner G, Carmichael I, Campbell AJD, Ryan U (2014) Longitudinal prevalence and faecal shedding of Chlamydia pecorum in sheep. Vet J 201:322-326. https://doi.org/10.1016/j.tvjl.2014.05.037
58. Giannitti F, Anderson M, Miller M, Rowe J, Sverlow K, Vasquez M, Cantón G (2016) Chlamydia pecorum: fetal and placental lesions in sporadic caprine abortion. J Vet Diagn Invest 28:184-189. https://doi.org/10.1177/10406 38715625729

59. Sammin D, Markey B, Bassett H, Buxton D (2009) The ovine placenta and placentitis—a review. Vet Microbiol 135:90-97. https://doi.org/10.1016/j. vetmic.2008.09.054

60. Struthers JD, Lim A, Ferguson S, Lee JK, Chako C, Okwumabua O, Cuneo $M$, Valle AM-D, Brower A (2021) Meningoencephalitis, vasculitis, and abortions caused by Chlamydia pecorum in a herd of cattle. Vet Pathol 58:549-577. https://doi.org/10.1177/0300985820985288

61. Jelocnik M, Frentiu FD, Timms P, Polkinghorne A (2013) Multilocus sequence analysis provides insights into molecular epidemiology of Chlamydia pecorum infections in australian sheep, cattle, and koalas. J Clin Microbiol 51:2625-2632. https://doi.org/10.1128/JCM.00992-13

62. Jelocnik M, Walker E, Pannekoek Y, Ellem J, Timms P, Polkinghorne A (2014) Evaluation of the relationship between Chlamydia pecorum sequence types and disease using a species-specific multi-locus sequence typing scheme (MLST). Vet Microbiol 174:214-222. https://doi. org/10.1016/j.vetmic.2014.08.018

63. Jenkins C, Jelocnik M, Micallef ML, Galea F, Taylor-Brown A, Bogema DR, Liu M, O'Rourke B, Chicken C, Carrick J, Polkinghorne A (2018) An epizootic of Chlamydia psittaci equine reproductive loss associated with suspected spillover from native Australian parrots. Emer Microbes Infect 7:88. https://doi.org/10.1038/s41426-018-0089-y

64. Longbottom D, Coulter $\sqcup$ (2003) Animal chlamydioses and zoonotic implications. J Comp Pathol 128:217-244. https://doi.org/10.1053/jcpa. 2002.0629

65. Philips HL, Clarkson MJ (1998) Experimental infection of pregnant ewes with Chlamydia pecorum. Infect Immun 66:2818-2821. https://doi.org/10. 1128/IAl.66.6.2818-2821.1998

66. Kirkbride CA (1993) Diagnoses in 1,784 ovine abortions and stillbirths. J Vet Diagn Invest 5:398-402. https://doi.org/10.1177/104063879300500 316

67. Rzewuska M, Kwiecień E, Chrobak-Chmiel D, Kizerwetter-Świda M, Stefańska I, Gieryńska M (2019) Pathogenicity and virulence of Trueperella pyogenes: a review. Int J Mol Sci 20:2737. https://doi.org/10.3390/ijms2 0112737

68. Dennis SM (1974) Perinatal lamb mortality in Western Australia. 1. General procedures and results. Aust Vet J 50:443-449. https://doi.org/10.1111/j. 1751-0813.1974.tb06867.x

69. Hadfield J, Croucher NJ, Goater RJ, Abudahab K, Aanensen DM, Harris SR (2017) Phandango: an interactive viewer for bacterial population genomics. Bioinformatics 34:292-293. https://doi.org/10.1093/bioinformatics/ btx610

\section{Publisher's Note}

Springer Nature remains neutral with regard to jurisdictional claims in published maps and institutional affiliations.

\footnotetext{
Ready to submit your research? Choose BMC and benefit from:

- fast, convenient online submission

- thorough peer review by experienced researchers in your field

- rapid publication on acceptance

- support for research data, including large and complex data types

- gold Open Access which fosters wider collaboration and increased citations

- maximum visibility for your research: over $100 \mathrm{M}$ website views per year
}

At $\mathrm{BMC}$, research is always in progress.

Learn more biomedcentral.com/submissions 